\title{
How Classroom Environment and General Grit Predict Foreign Language Classroom Anxiety of Chinese EFL Students
}

\author{
Chengchen Li, Huazhong University of Science and Technology \\ iD https://orcid.org/0000-0002-7262-3309
}

lichengchen@hust.edu.cn

Jean-Marc Dewaele, Birkbeck, University of London

https://orcid.org/0000-0001-8480-0977

j.dewaele@bbk.ac.uk

\begin{abstract}
Interest in the role of learners' personality, emotions and the learning environment in foreign language (FL) learning has grown exponentially in the past decade. The introduction of personality psychology in the field of applied linguistics has led to the inclusion of a set of personality dimensions in research designs like resilience and grit, which have been shown to be significant predictors of FL achievement. The abrupt emergence of COVID-19 in 2020 forced universities around the world to move their courses online, which has been named Emergency Remote Teaching. The sudden change in FL learning environment offers a unique opportunity to researchers to investigate whether the relationships between learners' personality and classroom emotions in traditional 'in-person' classes, and the predictors of those emotions, also exist in the new online environments. The present study examined the foreign language classroom anxiety (FLCA) of Chinese secondary students at different instruction levels and its links with learner-internal and external factors, namely general grit and the classroom environment (CE) of the online English classes. A total of 1,526 Chinese secondary students completed an online questionnaire. Pearson correlation analyses and regression analyses revealed that general grit and CE predicted FLCA either independently or jointly. The findings are discussed and interpreted in the light of existing research on person-environment interaction. We identify avenues for further research and propose a number of pedagogical implications for optimizing online FL teaching.
\end{abstract}

Keywords: classroom environment, foreign language classroom anxiety, general grit, online language learning, person-environment interaction, personality psychology

This work is licensed under the Creative Commons Attribution-ShareAlike 4.0 International agreement (CC BY-SA 4.0). http://creativecommons.org/licenses/by-sa/4.0/
Journal for the Psychology of Language Learning

ISSN: 2642-7001

(2021) Volume 3, Issue 2, pp. 86-98 https://doi.org/10.52598/jp11/3/2/6 


\section{INTRODUCTION}

When the World Health Organisation declared COVID-19 a global pandemic on March 11th 2020, it had dramatic effects on social interaction around the world. Carefree mingling in public places was suddenly a thing of the past, social distancing became the norm, regional and national lockdowns were imposed, and people were confined to their homes. Schools and universities had to close their buildings and teaching was moved online in a hurry, forcing teachers and learners to adjust to a new two-dimensional reality on screen, with disembodied voices coming out of tinny loudspeakers in computers. Hodges et al. (2020) described this new and unexpected teaching context "emergency remote teaching" (ERT), namely "a temporary shift of instructional delivery to an alternate delivery mode due to crisis circumstances" (Hodges et al., 2020). They distinguished it from pre-existing online teaching, which had been developed gradually and systematically over a period of several years. Teachers and students who were thrown in ERT, in an atmosphere of uncertainty, fear and grief, needed resilience, grit, creativity, optimism and flexibility like never before. The silver lining of the disastrous pandemic, which has cost so many lives, is that it offered unique research opportunities. More specifically, it allowed researchers to compare learner emotions in 'inperson' and in ERT settings, and it could probe to what extent the new learning environment changed the relationships between learners' emotions and their sources (Resnik \& Dewaele, 2021). This has implications for teachers as the evidence revealed that ERT feels more emotionally disembodied from 'in-class' teaching and that students with lower levels of trait emotional intelligence and autonomy struggled more in this new environment. It is highly likely that other personality facets play a role, which might need strengthening if ERT is to become more permanent.

Second Language Acquisition (SLA) research on learner emotions has been growing exponentially in the past decade, influenced by Positive Psychology (Dewaele \& Li, 2020; MacIntyre \& Gregersen, 2012). New dependent and independent variables such as foreign language enjoyment (FLE) (Dewaele \& MacIntyre, 2014), trait emotional intelligence (Li, 2020) and grit (Teimouri et al., 2020) emerged in research designs, in addition to well-established ones such as foreign language classroom anxiety (FLCA) (Horwitz et al., 1986). Researchers focused on the complex relationships between learners' classroom emotions, personality dimensions and academic success in the foreign language (FL). Given the exceptional psychological pressure of the pandemic on learners and the unique character of ERT, we decided to collect data from learners in the new online environments to find out whether the relationships between learners' general grit, classroom environment and FLCA differed from traditional 'in-person' classes.

\section{LITERATURE REVIEW}

\section{The Interactive View in Psychology and SLA}

There has been a decades-long person-environment debate in personality psychology (Mischel, 1968) and social psychology. Some argue that personality is shaped by nature, others insist that nurture plays a more prominent role. However, in the past decade an increasing number of voices have been heard begging researchers to move beyond the person-environment debate and to look instead at interaction and integration of independent variables (e.g., Donnellan et al., 2009; Krueger, 2009; Lucas \& Donnellan, 2009; Roberts, 2009). It becomes increasingly clear that person-environment interaction plays a fundamental role for any personality theory (Funder, 2008). According to this view, a person and the environment are interactive and interconnected rather than independent, separate or simply competitive. In other words, human behaviors, experiences, processes, and phenomena are contingent on both their dispositions such as personality traits and the environment or situation they are in, i.e., depending on a non-additive combination of person attributes and situation attributes (Funder, 2008).

SLA research has gone through a similar evolution. The traditional decontextualized or context-independent focus of individual difference (ID) research has gradually been replaced by an ID-environment interaction view (Dewaele, 2009; Dörnyei \& Ryan, 2015; Gkonou, 2017; Williams et al., 2019). Such a person-environment approach is crucial in research on learner emotions which are dependent on learner-internal as well as learner-external variables and may have complex and short-, medium- and long-term antecedents. Thus, in the present study, we focus on the interaction between learner personality (i.e., general grit), 
classroom environment (CE) and their interactive effect on FLCA.

\section{Foreign Language Classroom Anxiety}

MacIntyre (2017) noted that FLCA is one of the most studied psychological dimensions in SLA since its introduction in the field by Horwitz et al. (1986). According to MacIntyre (2017), FLCA is both an internal state and a social construct. In other words, it is co-shaped by "internal psychological processes, cognition and emotional states along with the demands of the situation and the presence of other people" (p. 28). The main source of FLCA, according to Horwitz (2017) is the feeling of discomfort that language learners experience because they lack the linguistic means to present themselves authentically. Indeed, "presenting yourself to the world through an imperfectly controlled new language is inherently anxiety-provoking for some people" (p. 44).

The enduring interest in FLCA is undoubtedly linked to its (moderate) negative effects on progress and performance in the FL (MacIntyre, 2017). Three recent meta-analyses by Botes et al. (2020), Teimouri et al. (2019), and Zhang (2019) showed significant negative correlations between FLCA and achievement measures. Research into FLCA is motivated by a desire to understand the phenomenon better with the aim of informing the development of new pedagogical practices where its negative effect can be tempered.

Prior empirical research has identified a list of learnerinternal and learner-external factors for FLCA. FLCA has been found to be linked to a wide range of learner-internal variables, including sociobiological variables (e.g., age, gender, social class, age of onset of learning the FL), linguistic and attitudinal variables (e.g., foreign language proficiency, degree of multilingualism, attitude towards the FL, relative standing among peers) and psychological variables including personality (e.g., trait emotional intelligence, second language tolerance of ambiguity, introversion, neuroticism, and psychoticism) (Dewaele, 2013; Dewaele \& MacIntyre, 2014, 2019; Dewaele et al., 2008, Dewaele et al., 2018). In addition, some learnerexternal variables were also identified as predictors of FLCA, such as attitude towards the FL teacher, the use of the FL by the teacher and teacher predictability (e.g.,
Dewaele et al., 2018). Following the same paradigm, Jiang and Dewaele (2019) found in a Chinese English-as-aforeign-language (EFL) context that FLCA was more strongly predicted by learner-internal variables including second language (L2) proficiency, relative standing in the L2 class, and attitude towards the L2 than by learnerexternal variables. Similar results were obtained in a Spanish EFL context: FLCA was predicted by both learnerinternal and learner-external factors and learner-internal factors played a larger role in predicting anxiety (Dewaele et al., 2019). Similarly, in another large-scale study by Li et al. (2020), FLCA was found to be co-predicted by a combination of one learner-internal variable, namely trait emotional intelligence, and one learner-external variable, namely classroom environment. In addition, trait emotional intelligence was a stronger predictor of FLCA than classroom environment. Trait emotional intelligence was also included in the research design of Resnik and Dewaele (2021), in addition to learner autonomy. Data were collected from 510 European tertiary-level EFL learners about their FLE and FLCA during the pre-pandemic in-person classes and during their Emergency Remote English classes. Participants were found to report significantly lower levels of both FLE and FLCA in their ERT classes. More autonomous and more emotionally intelligent students reported lower FLCA in both in-person and ERT classes.

\section{Classroom Environment}

Classroom environment (CE) refers to "the atmosphere, ambience, tone, or climate that pervades classroom settings" (Dorman et al., 2006, p. 2). It plays an essential role in learning (Fraser, 1998; Jennings \& Greenberg, 2009), affecting how students think, feel and behave in the classroom (Li et al., 2021). A positive CE is characterized by "student cohesiveness, teacher support, self-involvement, investigation, task orientation, cooperation and equity" (Li et al., 2021, p. 3).

Research in general education has traditionally focused on the links between CE and students' cognitive and affective outcomes. Positive $\mathrm{CE}$ is associated with positive feelings, heightened attention, motivation and engagement in the learning environment, while negative $\mathrm{CE}$ is linked to negative feelings, inattention and lack of engagement in learning activities (Hamre \& Pianta, 2007; Harvey, 2004; Reyes et al., 2012). General grit, like trait emotional 
intelligence and autonomy, can help students survive in a negative CE (see also next section). Classroom practices and the social relationships between all participants shape the $\mathrm{CE}$ and they are both influencing and influenced by learner and teachers' emotions (Dewaele, 2020; Joe et al., 2017).

A number of SLA researchers have sought to understand the relationship between CE and student emotions. Khajavy et al. (2018), for instance, uncovered a positive relationship between $\mathrm{CE}$ and enjoyment as well as a negative relationship between $\mathrm{CE}$ and anxiety among a group of 1,528 secondary Iranian EFL learners. In another study in a Chinese EFL context, Li et al. (2021) found that both FLE and FLCA were predicted by $\mathrm{CE}$ and trait emotional intelligence jointly. The conceptual assumptions and empirical findings provide robust evidence for the links between CE and FL emotions.

\section{Grit}

Grit is a personality trait that is essential to human success and performance across various academic and nonacademic domains (Credé et al., 2017; Duckworth et al., 2007). It has been defined as a compound trait characterized by "perseverance and passion for long-term goals" (Duckworth et al., 2007, p. 1087). Correspondingly, Duckworth et al. (2007) developed a 12-item Grit Scale and identified two lower-order constituent constructs: (1) Consistency of interest, defined as an individual's longlasting passion for a long-term goal despite the challenges, obstacles, failures, frustration or adversity they may encounter, and (2) Perseverance of effort, which refers to an individual's inclination to invest continuous efforts in pursuit of a long-term goal. Duckworth and Quinn (2009) then developed and validated a Short Grit Scale consisting of eight items measuring the same two factors.

Grit has started to attract attention from SLA researchers very recently for its potential predictive effects on L2 achievement (e.g., Alamer, 2021; Elahi Shirvan, 2021; Feng \& Papi, 2020; Keegan, 2017; Liu \& Wang, 2021; Wei et al., 2020; Yamashita, 2018). Current grit research in SLA has mainly been focused on the following four aspects: (1) The factor structure of grit, (2) measurements of grit and their psychometric properties, (3) the predictive effect of grit on
L2 achievement, and (4) the correlates of grit including sociobiological variables and psychological variables.

As for the first and second aspects, both general and language-domain-specific grit have been addressed by SLA researchers. Khajavy et al. (2021), for example, investigated the general grit of 1,178 Iranian EFL learners and found that Duckworth and Quinn (2009)'s Grit Scale-Short Version (Grit-S) showed satisfactory construct validity in this sample and the original bi-dimensional grit construct was replicated. Khajavy et al. (2021) further argued that grit should be examined componentially rather than as a single whole. However, the reliability of the global grit scale as well as of its two subscales (Consistency of Interest and Perseverence of Effort) were low to border-line acceptable. Teimouri et al. (2020) further argued for the need to distinguish domain-general grit from language-domainspecific grit considering the contextual variations and their potential implications. Correspondingly, they provided a language-domain-specific measure of grit, developing and validating a 9-item L2 grit scale among 191 Persian-L1 English majors. Similarly, they confirmed a two-factor model with the $L 2$ grit scale. The factor of Perseverance of Effort was measured by five items, and the factor of Consistency of Interest was measured by four items. The contextualized scale showed acceptable psychometric properties including construct validity, discriminant validity, concurrent validity, predictive validity, as well as reliability. The $L 2$ grit scale was administered to and validated with 700 German-as-an-L3 learners from six secondary schools in China, confirming the two-factor structure and acceptable reliability for the overall L2 grit scale as well as the two subscales (Li \& Yang, 2021)

Regarding the association between grit and L2 achievement, divergent findings have emerged. In an Iranian EFL context, for instance, Khajavy et al. (2021) found no significant correlation between general grit (measured by the Grit-S) or its two components and L2 achievement. In contrast, Wei et al. (2019), using data from 832 Chinese EFL learners at secondary level, found that general grit was a significant positive predictor of English achievement ( $r=.26, p<.001)$, indicating that participants with higher levels of general grit were more likely to do well in English. Teimouri et al. (2020) differentiated L2 grit and general grit, finding that the former predicted L2 achievement significantly while the latter failed to predict L2 grit. A partially different finding emerged in $\mathrm{Li}$ and 
Yang (2021) where both general grit and L2 grit were significant predictors of general and subdomain language achievements, and the effect sizes of the latter were larger.

More research is needed on the exact relationship between grit and L2 achievement but it is clear that grit is linked to a set of sociobiological and psychological variables that are essential in L2 learning including classroom environment and the FL emotions under investigation. For example, Wei et al. (2019) found a positive relationship between general grit and foreign language enjoyment, with a medium size $(r=.53, p<.001)$, suggesting that participants who reported higher levels of general grit were more likely to enjoy the learning of English. Besides, a significant positive correlation was found between grit and the positivity of the classroom environment $(r=.14, p<.001)$. In other words, grittier students tended to perceive their classroom environment as more positive.

In another study, Lee (2020) investigated the general grit of 647 EFL learners in South Korea at secondary level and tertiary level. The two components of general grit were found to be positively related to L2 enjoyment and L2 willingness to communicate, with gradually smaller effect sizes at higher instruction levels.

Focusing on L2 grit, Teimouri et al. (2020) found it associated with L2 emotions and L2 motivation. Specifically, L2 grit was found to be negatively related to L2 anxiety $(r=-.35, p<.001)$, while positively linked to L2 joy $(r=.55, p<.001)$, L2 willingness to communicate $(r$ $=.42, p<.001)$ as well as intended effort $(r=.66, p<.001)$. This indicates that grittier L2 learners tended to experience less anxiety and more joy, were more inclined to put in extra effort in L2 learning and communicating in L2. Similar findings were obtained in Wei et al. (2020). L2 grit was found to be positively correlated with L2 joy $(r=.55, p$ $<.001)$.

The studies reviewed indicate that both classroom environment and L2 grit are closely linked to positive or negative FL emotions, and that all of them are linked to each other as well. However, it remains to be seen whether and how classroom environment and L2 grit are interconnected and how well they predict FL emotions including FLCA. FLCA is known to negatively affect language learning processes (MacIntyre, 2017) and L2 achievement (Botes et al., 2020; Teimouri et al., 2019; Zhang, 2019). A better understanding of its predictors could have important pedagogical implications.

\section{The Present Study}

The following two research questions (RQs) guided the study:

RQ1: What are the interrelationships between CE, students' general grit and FLCA?

RQ2: (How) Do CE and students' general grit copredict their emotional experience of FLCA?

\section{METHOD}

\section{Participants and Data Collection}

The data were collected during March and April 2020, when teaching and learning were switched online nationally due to the disruptive effects of the COVID-19 pandemic. We adopted convenience sampling. Specifically, the first author contacted the vice principal of a large private school in China. The principal agreed to assist in the data collection and forwarded the online questionnaire to headteachers via Wechat (a mainstream social media app) group. Those teachers who were willing to participate further forwarded the questionnaire to their own class Wechat group where parents were also included. Parents were informed of the nature, purpose, approximate time for completion, and anonymity of the survey as well as their rights to decline the invitation or withdraw any time. Consent was obtained from every student and their parent(s) before the student could proceed to fill in the online questionnaire.

The school is devoted to junior middle schooling and senior middle schooling. There were more than 10,000 oncampus students in total. Our final sample consisted of 387 $(25.36 \%)$ and $388(25.43 \%)$ students from Year 1 and Year 2 in junior middle school respectively, and 598 (39.19\%) and $153(10.02 \%)$ from Year 1 and Year 2 in senior middle school respectively. The mean age of the participants was $15.46(S D=.038)$ with a range from 13 to 20 . There were 877 male participants $(57.5 \%)$ and 649 (42.5\%) female participants. A total of 1,517 out of the 1,526 (99.4\%) participants belonged to the Han ethnic group. The participants at the same instruction level followed the same 
curriculum and syllabus. All the participants speak a local dialect or Mandarin as their L1, and English as their sole FL. None of the participants had stayed in an English-speaking country for more than a week. None of them had participated in any standardized English proficiency test. However, the students were asked to evaluate their proficiency levels in different language domains including listening, speaking, reading, and writing on a 1-10-point scale in the current survey. The average scores for these domains were $6.54(S D=1.85), 5.55(S D=2.78), 6.23(S D$ $=2.60)$, and $6.09(S D=3.21)$ respectively.

\section{Instrument}

A composite questionnaire was adopted to measure the three variables under discussion. All the items were answered on a 5-point Likert scale ranging from "1" (completely disagree) to " 5 " (completely agree). All the questionnaires were translated into Chinese to allow for full understanding. The translated version was checked by three colleagues in applied linguistics, who were required to assess the (1) conformity between the Chinese version and the original version, and (2) the fluency, accuracy, and appropriateness of the Chinese expressions in the items.

\section{Classroom Environment}

CE was measured with a short form of the What Is Happening in This Class (WIHIC) Questionnaire. The full version of WIHIC consists of 56 items and was developed by Fraser et al. (1986). Peng and Woodrow (2010) reformulated the items to fit into the L2 context and shortened it to 13 items assessing three dimensions, i.e., Teacher Support, Student Cohesiveness, and Task Orientation.

The short version of the WIHIC was rephrased to address the online learning environment in the current study. Example items measuring the three dimensions are "The teacher is patient in online English teaching," "Tasks designed in this online English class are useful," and "I am friendly to members of this online English class". The scale showed acceptable construct validity $\left(\Delta \chi^{2}(62)=813.965, p\right.$ $<.001, \mathrm{CFI}=.928, \mathrm{TLI}=.909, \mathrm{SRMR}=.05, \mathrm{RMSEA}=.08$, $95 \% \mathrm{CI}=.077,097 ; N=1,526$ ), supporting the three-factor structure of $\mathrm{CE}$ in the current online learning context. It also showed high global reliability $(\alpha=.90)$ as well as dimensional reliability (alphas $=.86, .77$, and .85 respectively for each dimension; $N=1,526)$. The factor loadings of the 13 items ranged from .53 to .87 .

\section{Grit}

Participants' grit was assessed using a short version of the Grit Scale (Grit-S) developed by Duckworth and Quinn (2009). It consists of eight items (including four reversescored ones) measuring two dimensions, namely the Consistency of Interest and the Perseverance of Effort. In the present study, the two-factor model was well supported $\left(\Delta \chi^{2}(19)=156.95, p<.001\right.$, CFI $=.964$, TLI $=.947$, RMSEA $=.06$, SRMR $=.04, N=1,526)$. The reliability alphas of the global scale and its two subscales were .80, 77, and .77 respectively. The factor loadings of the eight items ranged from .46 to .87 .

\section{Foreign Language Classroom Anxiety}

FLCA was assessed using a shortened Foreign Language Classroom Anxiety Scale (S-FLCAS). Dewaele and MacIntyre (2014) extracted eight items including two reverse-scored items from the original 33-item FLCAS developed by Horwitz et al. (1986). In the present study, the reliability was high $(\alpha=.90)$. The S-FLCAS also showed good construct validity $\left(\Delta \chi^{2}(20)=250.187, p<.001\right.$, CFI $=.962, \mathrm{TLI}=.947, \mathrm{SRMR}=.03, \mathrm{RMSEA}=.08,95 \% \mathrm{CI}$ $=.075,095 ; N=1,526)$, confirming the unifactorial nature of FLCA (Botes et al., 2021). The factor loadings of the eight items ranged from .68 to .79 .

\section{Data Analysis}

Preliminary analyses of the data included descriptive analyses as well as normality tests for each observed variable. Then, we conducted Pearson correlation analyses to check the relationships between general grit, $\mathrm{CE}$, and FLCA. Finally, we conducted a linear regression with interactive effect checked. More specifically, first, CE, general grit and FLCA were standardized. The interaction variable was then created by multiplying standardized $\mathrm{CE}$ and standardized general grit. Finally, standardized CE, standardized grit, and the interaction variable were all 
entered into the same regression model as co-predictors for standardized FLCA, and multicollinearity was tested.

RESULTS

\section{Descriptive Results}

The descriptive results as well as normality test results are presented in Table 1. Participants reported having moderate levels of general grit and FLCA, and perceiving a relatively positive classroom environment in their online English classes.

Table 1. Profiles of General Grit, CE, and FLCA

\begin{tabular}{lcccccc}
\hline & Min. & Max. & $M$ & $S D$ & Skewness & \multicolumn{2}{c}{ Kurtosis } \\
\hline General grit & 1.00 & 5.00 & 3.19 & .59 & .432 & .78 \\
CE & 1.00 & 5.00 & 3.58 & .62 & -.562 & 1.14 \\
FLCA & 1.00 & 5.00 & 3.05 & .88 & -.320 & -.09 \\
\hline
\end{tabular}

Note. SE for Skewness $=.063 ;$ SE for Kurtosis $=.125$.

\section{Interrelationships Between Students' General Grit, Perceptions of CE and FLCA}

Pearson correlation results show that FLCA was negatively related to both general grit and $\mathrm{CE}$, both with a small-tomedium effect size $(r=-.37, p<.001 ;-.24, p<.001$ respectively) (Plonsky \& Oswald, 2014). This suggests that participants who reported higher levels of general grit or perceived their English classes as more positive in terms of the classroom environment were more likely to experience low levels of FLCA.

The results also show a positive small-to-medium relationship between general grit and $\mathrm{CE}(r=.313, p<.001)$, indicating that students who reported having higher levels of general grit tended to perceive their English classes more positive in their environment.

\section{The Joint Predictive Effects of CE and General Grit on FLCA}

The regression results are presented in Table 2 . The proposed model fits the data well $(R=.405, F(2)=99.51, p$ $<.001$ ), suggesting that participants' perceptions of classroom environment and their own general grit could interact with each other and co-predict their FLCA. In addition, in the model, general grit was the strongest predictor of FLCA $(\beta=-.322, p<.001)$, followed by CE $(\beta$ $=-.135, p<.001)$ and their interaction variable $(\beta=-.071$, $p<.01)$. This indicates that $\mathrm{CE}$ and general grit could predict FLCA either individually or jointly and that the independent predictive effect of general grit outweighed the independent predictive effect of $\mathrm{CE}$ and the interactive effect between general grit and CE on FLCA.

Table 2. The Interactive Effects of CE and General grit on FLCA

\begin{tabular}{|c|c|c|c|c|c|c|c|c|c|c|}
\hline \multirow[b]{2}{*}{ Predictor } & \multirow[b]{2}{*}{$R$} & \multicolumn{2}{|l|}{ Fit Index } & \multicolumn{3}{|c|}{ Coefficient } & \multicolumn{2}{|c|}{$\begin{array}{c}95 \% \mathrm{Cl} \\
\text { for } B\end{array}$} & \multicolumn{2}{|c|}{$\begin{array}{c}\text { Collinearity } \\
\text { Statistics }\end{array}$} \\
\hline & & $\begin{array}{c}\text { Adjusted } \\
R^{2} \\
\end{array}$ & $F$ & $\beta$ & $B$ & $t$ & lower & upper & Tolerance & VIF \\
\hline CE & & & & -.135 & -.136 & $-5.48^{* * *}$ & -.184 & -.087 & .898 & 1.114 \\
\hline General grit & .405 & .162 & $99.51^{* * *}$ & -.322 & -.324 & $-12.90^{\star \star *}$ & -.373 & -.275 & .884 & 1.131 \\
\hline $\mathrm{CE}^{*}$ General grit & & & & -.071 & -.058 & $-2.99^{* *}$ & -.096 & -.020 & .968 & 1.033 \\
\hline
\end{tabular}

Note. Outcome variable $=$ FLCA 


\section{DISCUSSION}

The first RQ addressed the interrelationships between CE, student general grit and FLCA. We found that FLCA was negatively related to students' perceptions of CE, echoing the findings obtained in the study by Li et al. (2020) in faceto-face classroom settings among secondary-level and tertiary-level students. It, thus, seems that both in online and face-to-face classroom settings, CE has a close link with students' FLCA. In other words, students feel less anxious in those classrooms with a positive environment characterized by teacher support, student cohesiveness, and task orientation (Peng \& Woodrow, 2010). It is not surprising that a student would feel more relaxed and psychologically safe in a supportive, well-organized, and engaging learning environment (Dewaele, 2020).

We also found a negative relationship between students' FLCA and general grit, dovetailing with the finding of the relationship between L2 grit and L2 anxiety in the study by Teimouri et al. (2020) — with a similar effect size. This indicates that both general grit and L2-domain-specific grit are significant predictors of students' FLCA. In other words, grittier students tend to experience less anxiety in the learning of an FL.

In line with the findings in Wei et al. (2020), a positive relationship between grit and $\mathrm{CE}$ also emerged in an online learning context, representing a small-to-medium effect size. This indicates that students' perceptions of CE may be linked to their personality, grit in particular. In other words, those students with higher levels of grit tended to perceive their FL classes as being a more positive environment. One possible explanation for this is that they had a "thicker skin" and were less likely to be upset by banter, teasing, or corrections by the teacher and may have been more likely to join in classroom discussions expressing their opinions without fear. The similarity in relationships between personality variables and learner emotions in online learning contexts as well as in face-to-face classroom settings confirms the patterns in Resnik and Dewaele (2021), where EFL learners who scored high on trait emotional intelligence and autonomy reported significantly lower levels of FLCA, and higher levels of enjoyment both in online classes and in the face-to-face classroom setting.

The second RQ pertains to the person-environment interaction (exemplified by the combination of general gritCE) and its effect on student FLCA. We found that the proposed regression model fit the data well, indicating that
CE and students' general grit predicted FLCA either independently or jointly. When entered into the same model, the independent effect of general grit $(\beta=-.322)$ outweighed that of $\operatorname{CE}(\beta=-.135)$ as well as their interactive effect $(\beta=$ -.071). This echoes the findings on the distinctive effects of trait emotional intelligence and CE on FLCA in Li et al. (2021) and of the learner-internal variables and learnerexternal variables on FLCA in Jiang and Dewaele (2019). It thus seems that both in face-to-face and in online EFL contexts, FLCA may be more strongly predicted by learnerinternal factors (such as Neuroticism) than by learnerexternal factors, again confirming previous research on learner emotions in face-to-face classroom settings (Dewaele et al., 2018; Dewaele \& MacIntyre, 2019).

Mirroring the person-environment interaction research in personality psychology as well as in social psychology, the current study exemplified how learner personality interacts with environmental factors to co-shape learners' emotional experiences. Future research could probe further into other aspects of learner personality (e.g., resilience, academic buoyancy, self-control, curiosity, and risk-taking). It would also be worth examining whether and how they interact with environmental factors at different levels (e.g., specific tasks in the classroom, classroom, school and social environment) to co-shape learner emotions (e.g., enjoyment, joy, boredom, shame, pride, and guilt). More research is also needed on the interactions between personality variables and socio-psychological variables in the learning of FL (e.g., attitudes, motivation, attention, learning strategies, and engagement) which may directly or indirectly affect performance and achievement in the FL. The findings also indicate that although FLCA is a language-domain-specific construct, it has a close link to learners' general personality, and more specifically the level of neuroticism or trait anxiety (cf. Dewaele, 2013).

The findings also have some pedagogical implications. FL teachers need to be aware that FLCA is debilitating and that there is no magic wand to turn an anxious student into a non-anxious one. What teachers can do is create a CE where students feel safe and where mutual trust and solidarity develops between the teachers and student, and between students themselves. Teacher humor and judicious praise, combined with linguistic challenges that are neither overly hard nor overly easy can boost students' enjoyment and will allow anxious students to shake off the paralyzing effects of FLCA. It may even help them to become gradually grittier in the FL class. 
The findings also have some implications for grit researchers. It appears that general grit is part of a series of psychological variables that interact with contextual variables that end up shaping learners' FLCA, which in turn will affect FL performance and development. It is important to point out that none of the interacting variables are entirely stable and that they influence each other. In other words, general grit may play a more important role in a negative emotional CE where FLCA may be exacerbated by poor pedagogical practices. Such an environment may force learners to become grittier and to control their FLCA, or drop out of the class (Dewaele \& Thirtle, 2009). General grit may have less effect in a positive, low-threat CE. This could also explain the diverging findings about the effect of general grit in the literature. Similar patterns have been observed about other personality traits. Dewaele and Furnham (2000) for example, reported that extraverts' superior stress-resistance served them well in maintaining a good level of fluency in FL production in a stressful situation but that it made no difference in a non-stressful situation.

The current study is not without limitations. Firstly, the use of self-reported data means that social desirability may slightly distort participants' responses in the questionnaire survey. Secondly, while personality traits like grit are universal, they may be more highly regarded and encouraged in some cultures, thus occupying a slightly different place in the order of importance in determining FL learners' emotions and behavior. While the broad effects of grit seem similar across cultures, we cannot exclude that differences exist at a more granular level. Finally, caution is needed when interpreting the findings obtained during exceptional times. Indeed, the pandemic has weighed heavily on both learners and teachers who have all been facing periods of social isolation, whose family members and themselves possibly also suffered from economic hardship, from mental and physical health issues, and who may have had to cope with loss and grief.

\section{CONCLUSION}

We pointed out in the introduction that one of the very few silver linings of the global pandemic was that it presented applied linguists with a unique opportunity to expand the scope of research into FL learner emotions and psychology. Most existing research had been carried out inside physical classrooms, with smells of chalk, of whiteboard pens, sitting on chairs at classroom desks with the three-dimensional view of peers and teachers, the soundscape of school life, the pleasures of spontaneous friendly banter and the occasional conflict with peers or teacher. The abrupt move to Emergency Remote Teaching changed all that and led to the question whether the relationships between psychological, emotional, and social variables continued to exist in an environment where the only connection between learners and teacher is a digital one.

The current study confirmed early findings that relationships between psychological, social, and emotional variables continue to exist in an Emergency Remote Teaching environment (Resnik \& Dewaele, 2021). Levels of FLCA of Chinese secondary EFL students were found to be predicted independently or jointly by general grit and by CE. A higher level of grit and a more positive perception of CE were linked to lower levels of FLCA. This finding offers further confirmation that while FLCA is a learner-internal variable that teachers cannot magically erase, they can create a positive classroom environment-both physical and digital - that can contribute to a mitigation of learners' FLCA.

To conclude, the current study offers further evidence of the richness of a person-environment approach to understand individual differences in a single learner emotion. It allowed us to probe the interactions between one learner-internal psychological variable, contextual variables and their interactive effect on learners' FLCA.

\section{Acknowledgments}

We would like to thank the school's vice principal and the teachers for allowing us access to participants. We are grateful that the participants provided us with precious data. Many thanks also to the reviewers and guest editors for the constructive feedback.

\section{Authors' contributions}

CL designed the study, completed the data collection and worked on the data analysis. CL and JMD drafted the manuscript and participated in the interpretation of the results. Both authors read and approved the final manuscript. 


\section{Ethics Approval \& Consent to Participate}

Consent was obtained from the school vice principal, EFL teachers, student participants, and their parent(s) prior to data collection.

\section{Funding}

This study was supported by National Social Science Foundation of China [Grant No. 19CYY017] and "the Fundamental Research Funds for the Central Universities" in China [Grant No. 2019kfyXJJS150].

\section{REFERENCES}

Alamer, A. (2021). Grit and language learning: construct validation of L2-Grit scale and its relation to later vocabulary knowledge. Educational Psychology, 41(5), 544-562. https://doi.org/10.1080/01443410.2020.1867076

Al-Hoorie, A. H., \& Macintyre, P. D. (Eds.) (2020). Contemporary language motivation theory: 60 years since Gardner and Lambert (1959). Multilingual Matters.

Botes, E., Dewaele, J.-M., \& Greiff, S. (2020). The foreign language classroom anxiety scale and academic achievement: an overview of the prevailing literature and a meta-analysis. Journal for the Psychology of Language Learning, 2(1), 26-56.

Credé, M., Tynan, M. C., \& Harms, P. D. (2017). Much ado about grit: A meta-analytic synthesis of the grit literature. Journal of Personality and Social Psychology, 113(3), 492-511. https://doi.org/10.1037/pspp0000102

Dewaele, J.-M. (2009). Individual differences in second language acquisition. In W. C. Ritchie \& T. K. Bhatia (Eds.), The new handbook of second language acquisition (Vol. 2, pp. 623-646). Emerald Group Publishing.

Dewaele, J.-M. (2013). The link between foreign language classroom anxiety and psychoticism, extraversion, and neuroticism among adult bi- and multilinguals. The Modern Language Journal, 97(3), 670-684. https://doi.org/10.1111/j.15404781.2013.12036.x

Dewaele, J.-M. (2020). If classroom emotions were music, teachers would be conductors and learners would be members of the orchestra. In O. Mentz \& K. Papaja (Eds.), Focus on language: Challenging language learning and language teaching in peace and global education (pp. 8-10). Lit Verlag.

Dewaele, J.-M., \& Furnham, A. (2000). Personality and speech production: A pilot study of second language learners. Personality and Individual Differences, 28, 355-365. https://doi.org/10.1016/S0191-8869(99)00106-3

Dewaele, J.-M., \& Li, C. (2020). Emotions in second language acquisition: A critical review and research agenda. Foreign Language World, 1, 3449.

Dewaele, J.-M., \& MacIntyre, P. D. (2014). The two faces of Janus? Anxiety and enjoyment in the foreign language classroom. Studies in Second Language Learning and Teaching, 4, 237-274. https://doi.org/10.14746/ssllt.2014.4.2.5

Dewaele, J.-M. \& MacIntyre, P. D. (2019). The predictive power of multicultural personality traits, learner and teacher variables on foreign language enjoyment and anxiety. In M. Sato \& S. Loewen (Eds.), Evidence-based second language pedagogy: A collection of instructed second language acquisition studies (pp. 263-286). Routledge.

Dewaele, J.-M., Magdalena, A. F., \& Saito, K. (2019). The effect of perception of teacher characteristics on Spanish EFL learners' anxiety and enjoyment. The Modern Language Journal, 103(2), 412-427. https://doi.org/10.1111/modl.12555

Dewaele, J.-M., Petrides, K. V., \& Furnham, A. (2008). Effects of trait emotional intelligence and sociobiographical variables on communicative anxiety and foreign language anxiety among adult multilinguals: A review and empirical investigation. Language Learning, 58(4), 911- 
960. https://doi.org/10.1111/j.1467-

9922.2008.00482.x

Dewaele, J.-M., \& Thirtle, H. (2009). Why do some young learners drop foreign languages? A focus on learner-internal variables. International Journal of Bilingual Education and Bilingualism, 12(6), 635649. https://doi.org/10.1080/13670050802549656

Dewaele, J.-M., Witney, J., Saito, K., \& Dewaele, L. (2018). Foreign language enjoyment and anxiety: The effect of teacher and learner variables. Language Teaching Research, 22(6), 676-697. https://doi.org/10.1177/1362168817692161

Donnellan, M. B., Lucas, R. E., \& Fleeson, W. (2009). Introduction to personality and assessment at age 40: Reflections on the legacy of the personsituation debate and the future of person-situation integration [Editorial]. Journal of Research in Personality, 43(2), 117-119. https://doi.org/10.1016/j.jrp.2009.02.010

Dorman, J. P., Fisher, D. L., \& Waldrip, B. G. (2006). Classroom environment, students' perceptions of assessment, academic efficacy and attitude to science: A LISREL analysis. In F. Darrell \& K. M. Swe (Eds.), Contemporary approaches to research on learning environments: Worldviews (pp. 1-28). World Scientific.

Dörnyei, Z., \& Ryan, S. (2015). The psychology of the language learner revisited. Routledge.

Duckworth, A. L., Peterson, C., Matthews, M. D., \& Kelly, D. R. (2007). Grit: Perseverance and passion for long-term goals. Journal of Personality and Social Psychology, 92(6), 10871101. https://doi.org/10.1037/00223514.92.6.1087

Duckworth, A. L., \& Quinn, P. D. (2009). Development and validation of the short Grit Scale (Grit-S). Journal of Personality Assessment, 91(2), 166174. https://doi.org/10.1080/00223890802634290

Elahi Shirvan, M., Taherian, T., \& Yazdanmehr, E. (2021). L2 grit: a longitudinal confirmatory factor analysis-curve of factors model. Studies in Second Language Acquisition. Advance online publication.

https://doi.org/10.1017/S0272263121000590

Feng, L., \& Papi, M. (2020). Persistence in language learning: The role of grit and future self-guides. Learning and Individual Differences, 81, 1-10. https://doi.org/10.1016/j.lindif.2020.101904

Fraser, B. J. (1998). Classroom environment instruments: Development, validity and applications. Learning Environments Research, 1(1), 7-34. https://doi.org/10.1023/A:1009932514731

Fraser, B. J., Treagust, D. F., \& Dennis, N. C. (1986). Development of an instrument for assessing classroom psychosocial environment at universities and colleges. Studies in Higher Education, 11(1), 43-54. https://doi.org/10.1080/03075078612331378451

Funder, D. C. (2008). Persons, situations, and personsituation interactions. In O. P. John, R. W. Robins, \& L. A. Pervin (Eds.), Handbook of personality: Theory and research (pp. 568-580). Guilford Press.

Gkonou, C. (2017). Towards an ecological understanding of language anxiety. In C. Gkonou, M. Daubney, \& J.-M. Dewaele (Eds.), New insights into language anxiety: Theory, research and educational implications (pp. 135-155). Multilingual Matters.

Gregersen, T.S. (2005). Nonverbal cues: Clues to the detection of foreign language anxiety. Foreign Language Annals, 38, 388-400. https://doi.org/10.1111/j.19449720.2005.tb02225.x

Hamre, B. K., \& Pianta, R. C. (2007). Learning opportunities in preschool and early elementary classrooms. In R. C. Pianta, M. J. Cox, \& K. L. Snow (Eds.), School readiness and the transition to kindergarten in the era of accountability (pp. 49-83). Paul H. Brookes Publishing.

Harvey, S. T. (2004). Understanding the emotional environment of the classroom. [Unpublished doctoral dissertation] The University of Waikato. 
Hodges, C., Moore, S., Lockee, B., Trust, T., \& Bond, A. (2020). The difference between emergency remote teaching and online learning. Educause Review https://er.educause.edu/\%20articles/2020/3/thedifference-between-emergency-remote-teachingand-online-learning (accessed 27 July 2020).

Horwitz, E. K. (2017). On the misreading of Horwitz, Horwitz and Cope (1986) and the need to balance anxiety research and the experiences of anxious language learners. In C. Gkonou, M. Daubney, \& J.-M. Dewaele (Eds.), New insights into language anxiety (pp. 31-48). Multilingual Matters.

Horwitz, E. K., Horwitz, M. B., \& Cope, J. (1986).

Foreign language classroom anxiety. The Modern

Language Journal, 70(2), 125-132.

https://doi.org/10.1111/j.1540-

4781.1986.tb05256.x

Jennings, P. A., \& Greenberg, M. T. (2009). The prosocial classroom: Teacher social and emotional competence in relation to student and classroom outcomes. Review of Educational Research, 79(1), 491-525.

\section{https://doi.org/10.3102/0034654308325693}

Jiang, Y., \& Dewaele, J. M. (2019). How unique is the foreign language classroom enjoyment and anxiety of Chinese EFL learners? System, 82, 13-25. https://doi.org/10.1016/j.system.2019.02.017

Joe, H. K., Hiver, P., \& Al-Hoorie, A. H. (2017). Classroom social climate, self-determined motivation, willingness to communicate, and achievement: A study of structural relationships in instructed second language settings. Learning and Individual Differences, 53, 133-144. https://doi.org/10.1016/j.lindif.2016.11.005

Keegan, K. (2017). Identifying and building grit in language learners. English Teaching Forum, 55(3), 2-9.

Khajavy, G. H., MacIntyre, P. D., \& Barabadi, E. (2018). Role of the emotions and classroom environment in willingness to communicate. Studies in Second Language Acquisition, 40(3), 605-624. https://doi.org/10.1017/S0272263117000304
Khajavy, G. H., MacIntyre, P. D., \& Hariri, J. (2021). A closer look at grit and language mindset as predictors of foreign language achievement. Studies in Second Language Acquisition, 43(2), 379-402. https://doi.org/10.1017/S0272263120000480

Krueger, J. I. (2009). A componential model of situation effects, person effects, and situation-by-person interaction effects on social behavior. Journal of Research in Personality, 43(2), 127-136. https://doi.org/10.1016/j.jrp.2008.12.042

Lee, J. S. (2020). The role of grit and classroom enjoyment in EFL learners' willingness to communicate. Journal of Multilingual and Multicultural Development. Advance online publication. https://doi.org/10.1080/01434632.2020.1746319

Li, C. (2020). A positive psychology perspective on Chinese EFL students' trait emotional intelligence, foreign language enjoyment and EFL learning achievement. Journal of Multilingual and Multicultural Development, 41(3), 246-263. https://doi.org/10.1080/01434632.2019.1614187

Li, C., Dewaele, J.-M., \& Jiang, G. (2020). The complex relationship between classroom emotions and EFL achievement in China. Applied Linguistics Review, 11(3), 485-510. https://doi.org/10.1515/applirev$\underline{2018-0043}$

Li, C., Huang, J., \& Li, B. (2021). The predictive effects of classroom environment and trait emotional intelligence on foreign language enjoyment and anxiety. System, 96, 1-11. https://doi.org/10.1016/j.system.2020.102393

Li, C., \& Yang, Y. (2021). Domain-general grit and language-specific grit: Conceptual structures, measurements, and associations with achievement of German as an L3. Unpublished paper.

Li, J., Zhao, Y., Kong, F., Du, S., Yang, S., \& Wang, S. (2016). Psychometric assessment of the Short Grit Scale among Chinese adolescents. Journal of Psychoeducational Assessment, 36(3), 291-296. https://doi.org/10.1177/0734282916674858

Liu, E., \& Wang, J. (2021). Examining the relationship between grit and foreign language performance: 
Enjoyment and anxiety as mediators. Frontiers in Psychology.

https://doi.org/10.3389/fpsyg.2021.666892

Lucas, R. E., \& Donnellan, M. B. (2009). If the personsituation debate is really over, why does it still generate so much negative affect? Journal of Research in Personality, 43(2), 146-149. https://doi.org/10.1016/j.jrp.2009.02.009

MacIntyre, P. D. (2017). An overview of language anxiety research and trends in its development. In C. Gkonou, M. Daubney, \& J.-M. Dewaele (Eds.), New insights into language anxiety: Theory, research and educational implications (pp. 1130). Multilingual Matters.

Mischel, W. (1968). Personality and assessment. Wiley.

Peng, J., \& Woodrow, L. (2010). Willingness to communicate in English: A model in the Chinese EFL classroom context. Language Learning, 60(4), 834-876. https://doi.org/10.1111/j.14679922.2010.00576.x

Plonsky, L., \& Oswald, F. L. (2014). How big is “big”? Interpreting effect sizes in L2 research. Language Learning, 64(4), 878-912. https://doi.org/10.1111/lang.12079

Resnik, P., \& Dewaele, J.-M. (2021). Learner emotions, autonomy and trait emotional intelligence in 'inperson' versus emergency remote English foreign language teaching in Europe. Applied Linguistics Review. Advance online publication. https://doi.org/doi:10.1515applirev-2020-0096

Reyes, M. R., Brackett, M. A., Rivers, S. E., White, M., \& Salovey, P. (2012). Classroom emotional climate, student engagement, and academic achievement. Journal of Educational Psychology, 104(3), 700712. https://doi.org/10.1037/a0027268

Roberts, B. W. (2009). Back to the future: Personality and assessment and personality development. Journal of Research in Personality, 43(2), 137-145. https://doi.org/10.1016/j.jrp.2008.12.015

Saito, K., Dewaele, J.-M., Abe, M., \& In'nami, Y. (2018). Motivation, emotion, learning experience, and second language comprehensibility development in classroom settings: A cross-sectional and longitudinal study. Language Learning, 68(3), 709-743. https://doi.org/10.1111/lang.12297

Teimouri, Y., Goetze, J., \& Plonsky, L. (2019). Second language anxiety and achievement: A metaanalysis. Studies in Second Language Acquisition, 41(2), 363-387. https://doi.org/10.1017/S0272263118000311

Teimouri, Y., Plonsky, L., \& Tabandeh, F. (2020). L2 grit: Passion and perseverance for second-language learning. Language Teaching Research. Advance online publication.

https://doi.org/10.1177/1362168820921895

Wei, H., Gao, K., \& Wang, W. (2019). Understanding the relationship between grit and foreign language performance among middle school students: The roles of foreign language enjoyment and classroom environment. Frontiers in Psychology, 10, 1508 . https://doi.org/doi:10.3389/fpsyg.2019.01508

Wei, R., Liu, H., \& Wang, S. (2020). Exploring L2 grit in the Chinese EFL context. System, 93, 102295. https://doi.org/10.1016/j.system.2020.102295

Yamashita, T. (2018). Grit and second language acquisition: Can passion and perseverance predict performance in Japanese language learning? [unpublished master's thesis] University of Massachusetts.

Zhang, X. (2019). Foreign language anxiety and foreign language performance: A meta-analysis. The Modern Language Journal, 103(4), 763-781. https://doi.org/10.1111/modl.12590. 